\title{
The effect of tranexamic acid in patients with TBI: a systematic review and meta- analysis of randomized controlled trials
}

\author{
Chao-nan $\mathrm{Du}^{1 \dagger}$, Bo-xue Liư ${ }^{1 \dagger}$, Qing-fang $\mathrm{Ma}^{2}$ and Ming-fei Yang ${ }^{3^{*}}$
}

\begin{abstract}
To conduct a systematic review and meta-analysis and evaluate the effect of tranexamic acid in patients with traumatic brain injury. PubMed, EMBASE, and CENTRAL (Cochrane Central Register of Controlled Trials) were searched to identify randomized controlled trials and evaluate the effect of tranexamic acid in traumatic brain injury patients. The primary outcome was mortality. Two reviewers extracted the data independently. The random effect meta-analysis was used to estimate the aggregate effect size of $95 \%$ confidence intervals. Six randomized controlled trials investigating tranexamic acid versus placebo and 30073 patients were included. Compared with placebo, tranexamic acid decreased the mortality $(\mathrm{RR}=0.92 ; 95 \% \mathrm{Cl}, 0.87-0.96 ; p<0.001)$ and growth of hemorrhagic mass ( $R R=0.78 ; 95 \% \mathrm{Cl}, 0.61-0.99 ; p=0.04$ ). However, tranexamic acid could not decrease disability or independent, neurosurgery, vascular embolism, and stroke. Current evidence suggested that compared with placebo, tranexamic acid could reduce mortality and growth of hemorrhagic mass. This finding indicated that patients with traumatic brain injury should be treated with tranexamic acid.
\end{abstract}

Keywords: Traumatic brain injury, Tranexamic acid, Mortality, Disability

\section{Background}

Every year, it was estimated that more than 60 million individuals suffer from traumatic brain injury (TBI) all over the world for a variety of reasons [1]. TBI was a serious health problem and one of the main causes of death and disability worldwide. Study indicated that intracranial hemorrhage was a common complication of TBI, which increased the risk of death and disability [2]. The formation of microplots and vascular occlusion was common after brain injury [3]. Tranexamic acid (TXA) can inhibit fibrinolysis by competing with lysine residues on the surface of fibrin, thus stabilizing clots and blocking the interaction between plasmin and plasmin.

\footnotetext{
* Correspondence: iloveyoucmu@163.com

${ }^{\dagger}$ Chao-nan Du and Bo-xue Liu are co-first author

${ }^{3}$ Department of Neurosurgery, Qinghai Provincial People's Hospital, Xining, Qinghai, China

Full list of author information is available at the end of the article
}

Because of the potential role of TXA in reducing the size of hematoma and preventing secondary brain injury, TXA is considered as a possible treatment to improve the clinical outcome of TBI. However, the effects of TXA in patients with TBI remain controversial. So far, a randomized controlled trial (RCT), the CRASH-2 trial [4], reported that TXA could reduce the mortality, especially within $3 \mathrm{~h}$ in TBI patients. Indeed, another RCT CRASH-3 trial [5] further proved the above conclusions. In order to provide the latest and most convincing evidence, we systematically reviewed the existing literature to study whether TXA could reduce the mortality of patients with TBI. The secondary objective was to evaluate the effects of TXA on disability or independent, vascular embolism (including myocardial infarction, deep vein thrombosis, and pulmonary embolism), and stroke in TBI patients. 


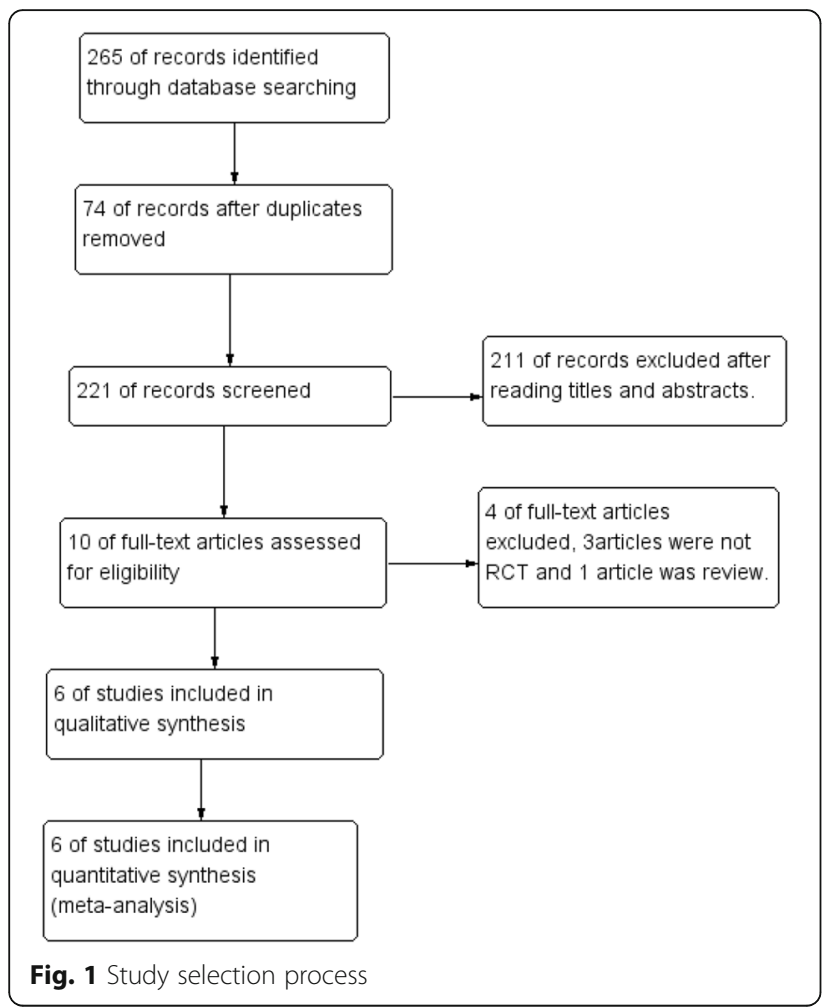

\section{Literature search and selection criteria}

The meta-analysis was conducted in accordance with the Cochrane Handbook for Systematic Reviews of Interventions [6] and reported in accordance with the PRISMA (preferred reporting item for system review and meta-analysis) statement [7]. PubMed, EMBASE, and CENTRAL (Cochrane Central Register of Controlled Trials) were searched through January 3, 2020, with no restrictions. The following search terms were used "traumatic brain injury", "Glasgow Coma Scale", "Glasgow Outcome Scale", "craniocerebral trauma", "acute brain injury", and "tranexamic acid". Two independent investigators (CD and $\mathrm{BL}$ ) conducted a preliminary search, deleted duplicate records, screened the relevance of titles and summaries, and identified articles requiring further evaluation. We reviewed the full-text articles to assess eligibility. Disagreements were resolved by discussion with another investigator.

The inclusion criteria were as follows: (1) population: patients with TBI; (2) intervention: TXA $(1 \mathrm{~g}$ in $100 \mathrm{ml}$ of normal saline); (3) comparison: placebo; (4) outcome: the primary outcome was mortality, the second outcomes included disability or independent, growth of hemorrhagic mass, neurosurgery, vascular embolism (including myocardial infarction, deep vein thrombosis, and pulmonary embolism) and stroke; and (5) design: RCTs.

Table 1 Characteristics of the included studies

\begin{tabular}{|c|c|c|c|c|c|c|c|c|c|}
\hline \multirow{2}{*}{\multicolumn{2}{|c|}{ Trail }} & \multirow[t]{2}{*}{ Country } & \multicolumn{4}{|c|}{ Tranexamic acid group } & \multicolumn{3}{|c|}{ Placebo group } \\
\hline & & & Number & Age (years) & Method & Follow-up & Number & Age (years) & Follow-up \\
\hline 1 & $\begin{array}{l}\text { Chakroun-Walha } \\
2019 \text { [11] }\end{array}$ & Tunisia & 96 & $44.0 \pm 20.0$ & $\begin{array}{l}\text { VTA was administered as soon } \\
\text { as possible, with a first dose of } \\
1 \mathrm{~g} \text { in } 100 \mathrm{ml} \text { of normal saline } \\
\text { in } 10 \mathrm{~min} \text { and then with a } \\
\text { maintenance dose of } 1 \mathrm{~g} \text { per } \\
500 \mathrm{ml} \text { of normal saline for } 8 \mathrm{~h}\end{array}$ & 28 days & 84 & $39 \pm 18$ & 28 days \\
\hline 2 & $\begin{array}{l}\text { CRASH-2 trial } \\
\text { collaborators } 2011 \text { [10] }\end{array}$ & $\begin{array}{l}\text { India and } \\
\text { Colombia }\end{array}$ & 123 & $36.0 \pm 14.0$ & $\begin{array}{l}\text { VTA was administered with the } \\
\text { first dose of } 1 \mathrm{~g} \text { in } 100 \mathrm{ml} \text { of } \\
\text { normal saline in } 10 \mathrm{~min} \text { and then } \\
\text { with a maintenance dose of } 1 \mathrm{~g} \text { per } \\
1000 \mathrm{ml} \text { of normal saline for } 8 \mathrm{~h}\end{array}$ & 28 days & 126 & $37 \pm 14$ & 28 days \\
\hline 3 & $\begin{array}{l}\text { CRASH-3 trial } \\
\text { collaborators } 2019 \text { [5] }\end{array}$ & UK & 4613 & $41.7 \pm 19.0$ & $\begin{array}{l}\text { VTA was administered with the } \\
\text { first dose of } 1 \mathrm{~g} \text { in } 100 \mathrm{ml} \text { of normal } \\
\text { saline over } 10 \mathrm{~min} \text {, followed by an } \\
\text { intravenous infusion of } 1 \mathrm{~g} \text { over } 8 \mathrm{~h}\end{array}$ & 28 days & 4514 & $41.9 \pm 19.0$ & 28 days \\
\hline 4 & Fakharian 2018 [12] & Iran & 74 & $42.3 \pm 18.3$ & $\begin{array}{l}\text { VTA was administered with the } \\
\text { first dose of } 1 \mathrm{~g} \text { in } 100 \mathrm{ml} \text { of normal } \\
\text { saline in } 10 \mathrm{~min} \text { and then with a } \\
\text { maintenance dose of } 1 \mathrm{~g} \text { per } \\
1000 \mathrm{ml} \text { of normal saline for } 8 \mathrm{~h}\end{array}$ & 3 months & 75 & $39.3 \pm 18.1$ & 3 months \\
\hline 5 & Roberts 2013 [4] & UK & 10060 & $34.6 \pm 14.1$ & $\begin{array}{l}\text { VTA (loading dose of } 1 \mathrm{~g} \text { of VTA } \\
\text { infused over } 10 \text { min, followed by } \\
\text { an intravenous infusion of } 1 \mathrm{~g} \\
\text { over } 8 \mathrm{~h} \text { ) }\end{array}$ & 28 days & 10,067 & $34.5 \pm 14.4$ & 28 days \\
\hline 6 & $\begin{array}{l}\text { Yutthakasemsunt } \\
2013 \text { [13] }\end{array}$ & Thailand & 120 & $34.8 \pm 16.0$ & $\begin{array}{l}\text { VTA (loading dose of } 1 \mathrm{~g} \text { over } 30 \mathrm{~min} \\
\text { followed by a maintenance dose of } \\
1.0 \mathrm{~g} \text { infused over } 8 \mathrm{~h} \text { ) }\end{array}$ & 24-32h & 118 & $34.1 \pm 15.3$ & $24-32 \mathrm{~h}$ \\
\hline
\end{tabular}




\section{a}

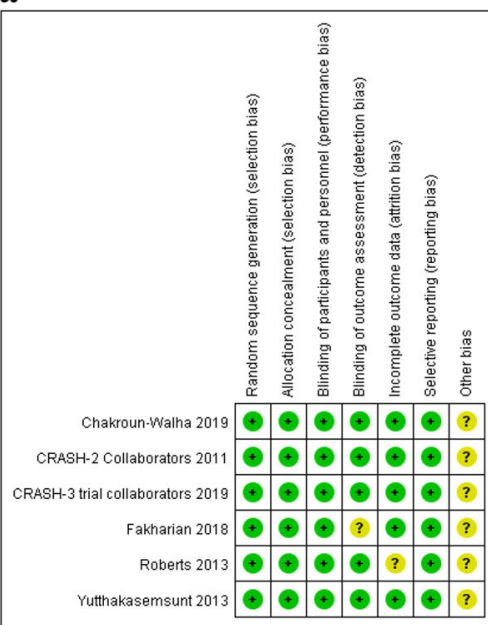

b

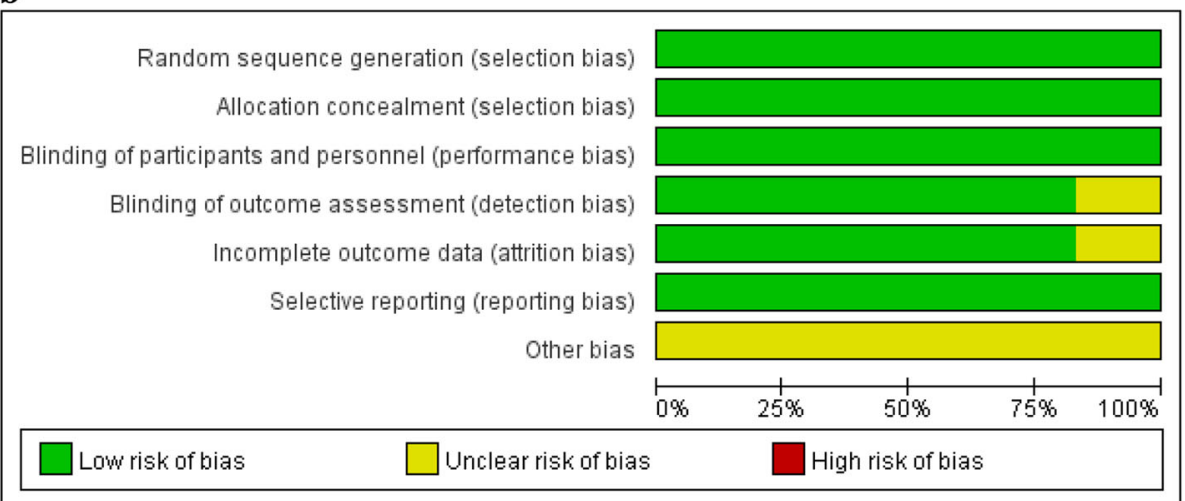

Fig. 2 Risk of bias graph and bias summary. $\mathbf{a}+=$ low risk, and ? = uncertain risk.

\section{Data extraction and quality assessment}

Two reviewers (CD and $\mathrm{BL}$ ) extracted data independently. The data were extracted from each study as follow: first author, year of publication, country, intervention characteristics (number of patients, age, intervention methods), comparison characteristics (number of patients, age, comparison methods), and data on primary and secondary outcomes. When we found duplicate reports of the same trial, we retained only the most complete study. Disagreements were solved by discussion with another reviewer. The Cochrane risk of bias tool was adopted by two independent reviews to assess the risk of bias for each RCT [8].

\section{Statistical analysis}

Differences were expressed as relative risk (RR) with 95\% confidence interval (CI). Meta-analyses were performed using a random-effects model accounting for heterogeneity. The statistical heterogeneity of different trials was evaluated by $\mathrm{I}^{2}$ statistic [9]. Study with $\mathrm{I}^{2}$

Table 2 Quality assessment of the included trials

\begin{tabular}{lllllll}
\hline Criteria & Design & \multicolumn{2}{l}{ Quality assessment } & & \\
\cline { 3 - 6 } & & Concealment & Intention-to-treat analysis & Blinding & $\begin{array}{c}\text { Outcome reporting bias } \\
\text { Quality of } \\
\text { evidence }\end{array}$ \\
\hline Chakroun-Walha 2019 [11] & Randomized trials & Yes & Yes & Yes & None detected & High \\
CRASH-2 trial collaborators 2011 [10] & Randomized trials & Yes & Yes & Yes & None detected & High \\
CRASH-3 trial collaborators 2019 [5] & Randomized trials & Yes & Yes & Yes & None detected & High \\
Fakharian 2018 [12] & Randomized trials & Yes & Yes & Yes & None detected & High \\
Roberts 2013 [2013] & Randomized trials & Yes & Yes & Yes & None detected & High \\
Yutthakasemsunt 2013 [13] & Randomized trials & Yes & Yes & Yes & None detected & High \\
\hline
\end{tabular}




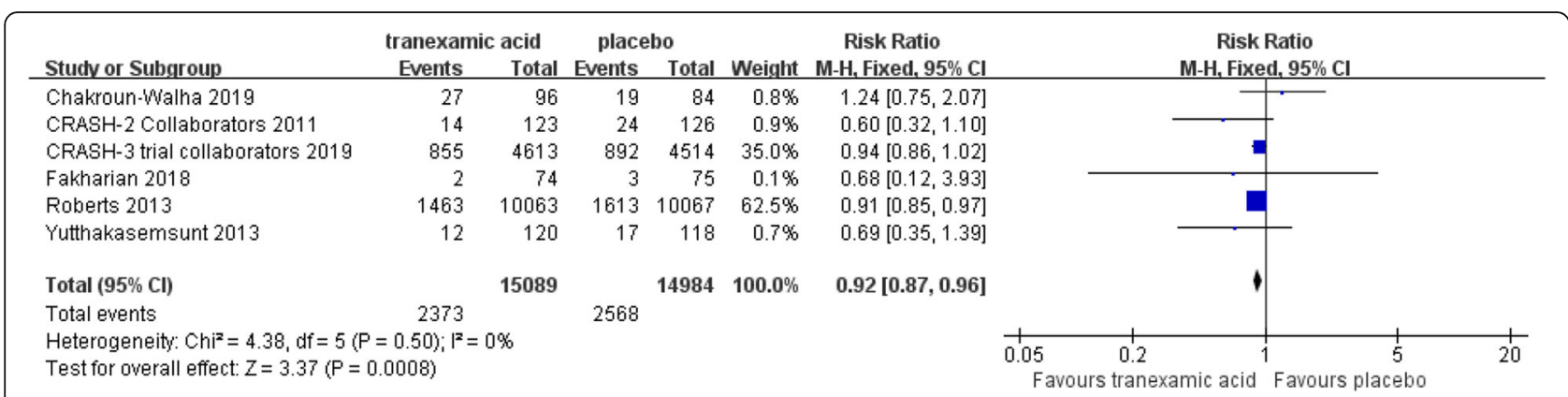

Fig. 3 Forest plot of the meta-analysis of mortality. The results indicated that tranexamic acid could decrease the mortality significantly

values over $50 \%$ was considered to have high heterogeneity [9]. For the main outcome of mortality, subgroup analysis was conducted according to the characteristics of patients (Glasgow Coma Scale [GCS]3-8 and GCS 915). $p<0.05$ was considered statistically significant. All statistical analyses were performed using Revman 5.3 (Nordic Cochrane Center).

\section{Study selection and characteristics}

A total of 265 records were identified from the initial database search. Seventy-four records were excluded from duplicate records, and 211 were excluded for a variety of reasons, due to titles and abstracts (comments, letters, or not related to analysis). The remaining 10 full-text articles were assessed eligible, and four were excluded. Finally, 6 studies $[4,5,10-13]$ were included in this meta-analysis. The selection process is shown in Fig. 1. The main characteristics of the included studies are shown in Table 1. These included studies were published from 2011 to 2019, and the sample sizes were 30073 (TXA group, 15089; placebo group, 14984). All studies were published in English.

All included studies reported mortality [4, 5, 10-13], three studies reported growth of hemorrhagic mass [10, $12,13]$, four reported disability or dependent $[4,5,12,13]$, three studies reported neurosurgery [11-13], three reported vascular embolism $[4,5,11]$, and three reported stroke $[4,5,13]$. Details of the risk of bias graph (Fig. 2a) and risk of bias summary (Fig. $2 \mathrm{~b}$ ) were presented. Overall, none of the study had high risk of bias (Table 2).

\section{Primary outcome}

The total number of mortalities was 4941 among the six trails. In TXA and placebo group, the mortality was respectively $15.7 \%$ (2373 of 15,089$)$ and $17.1 \%$ (2568 of 14 , 984). TXA decreased the mortality significantly ( $R R=$ 0.92; 95\% CI, 0.87-0.96; $p<0.001$; Fig. 3). No statistical heterogeneity was observed in the trial $\left(\mathrm{I}^{2}=0 \%\right)$. There was no significance of patients with GCS 9-15 (RR =

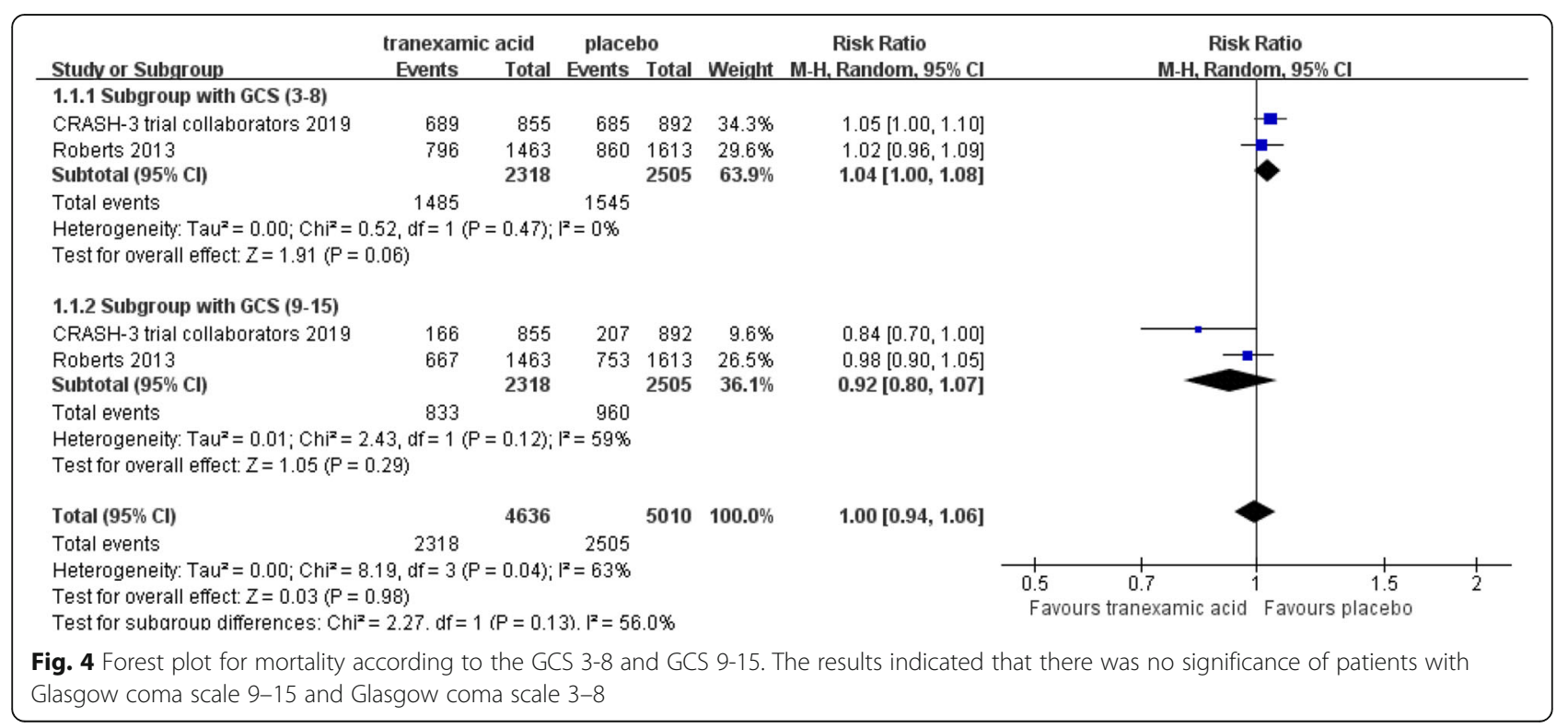




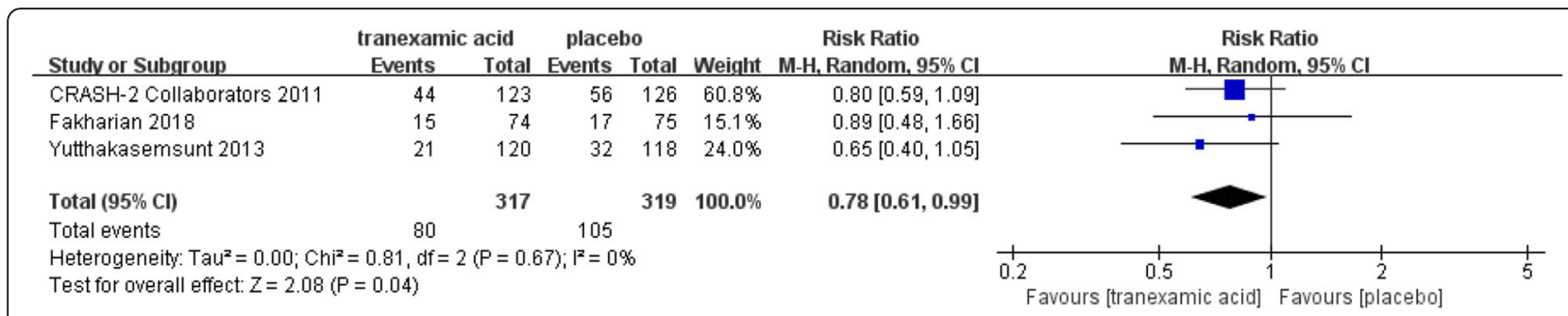

Fig. 5 Forest plot of the meta-analysis of growth of hemorrhagic mass. The results indicated that there was significant in growth of hemorrhagic mass

$0.92 ; 95 \% \mathrm{CI}, 0.80-1.07 ; p=0.29)$ and GCS $3-8(\mathrm{RR}=$ $1.04 ; 95 \%$ CI, 1.00-1.08; $p=0.06$; Fig. 4).

\section{Sensitivity analysis}

The meta-analysis of mortality had no heterogeneity among the included studies, and thus we did not perform sensitivity analysis.

\section{Secondary outcomes}

There was significance in growth of hemorrhagic mass $(\mathrm{RR}=0.78$; 95\% CI, 0.61-0.99; $p=0.04$; Fig. 5). However, there were no significant differences in disability or independent $(\mathrm{RR}=1.01 ; 95 \% \mathrm{CI}, 0.95-1.07 ; p=0.84$; Fig. 6), vascular embolism $(\mathrm{RR}=1.02 ; 95 \% \mathrm{CI}, 0.70-$ $1.48 ; p=0.92$; Fig. 6$)$, stroke ( $\mathrm{RR}=1.07$; 95\% CI, $0.78-$ $1.48 ; p=0.67$; Fig. 6$)$, and neurosurgery $(\mathrm{RR}=0.99 ; 95 \%$

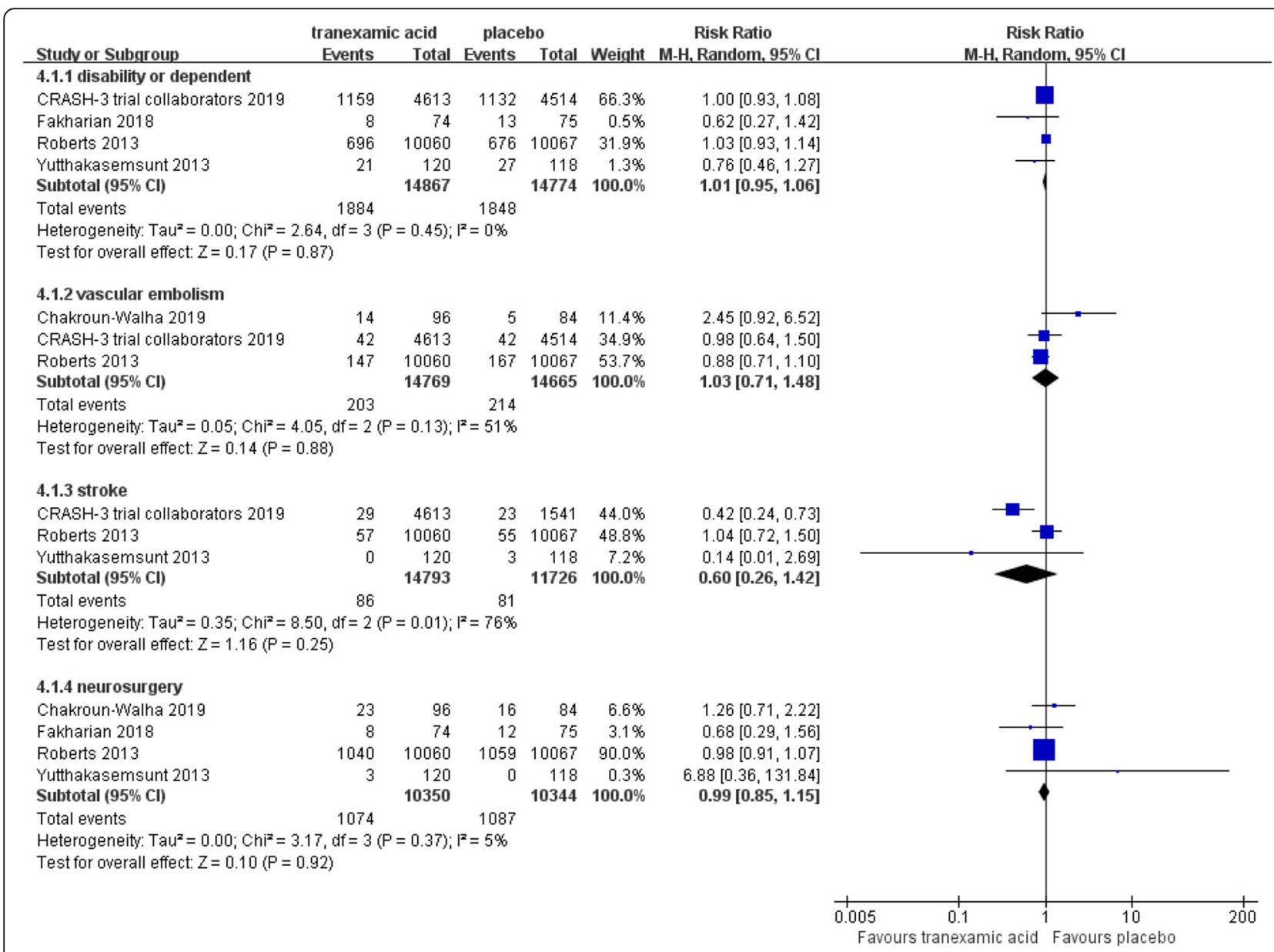

Fig. 6 Forest plot of the meta-analysis of disability or independent, vascular embolism, stroke and neurosurgery. The results indicated that there were no significant differences in disability or independent, vascular embolism, stroke, and neurosurgery between tranexamic acid and placebo 
CI, $0.85-1.15 ; p=0.92$; Fig. 6) between TXA and placebo.

\section{Main findings and comparison with previous studies}

Compared with placebo, TXA (a first dose of $1 \mathrm{~g}$ in 100 $\mathrm{ml}$ of normal saline in 10 to $30 \mathrm{~min}$ after admission) could reduce the mortality and growth of hemorrhagic mass of patients with TBI. However, neither GCS 3-8 nor GCS 9-15 could reduce the risk. In addition, there was no significant difference between TXA and placebo in disability or independent, neurosurgery, vascular embolism, and stroke.

Several meta-analysis comparing TXA and placebo had been published [14-17]. Two meta-analysis of RCTs indicated that TXA had significantly reduced intracranial hemorrhage progression but not mortality $[14,17]$. The other two meta-analysis further testified the progress of intracranial hemorrhage; however, the two meta-analysis demonstrated that TXA was associated with substantially reduced mortality $[15,16]$. These above metaanalysis [14-17] with TBI, and proved that TXA could reduce the mortality. Moreover, subgroup analysis found that treatment with TXA between GCS 3-8 and GCS 915 did not reach significance.

Crash-2 trials $[10,18]$ showed that in TBI patients, TXA was given early administration (within $3 \mathrm{~h}$ after injury) significantly reduced mortality. In CRASH-3 trails [5], the safety of TXA in TBI patients had been confirmed and treatment within $3 \mathrm{~h}$ could decrease the mortality. Our data indicated that there was significance in growth of hemorrhagic mass ( $\mathrm{RR}=0.78$; 95\% CI, 0.61$0.99 ; p=0.04)$. The current evidences showed that TXA had the effect of reducing bleeding and mortality. Study showed that Africa and Southeast Asia were the high incidence areas of TBI [1]. Two studies $[4,5]$ in this metaanalysis included the population of Africa and Southeast Asia, proved the effect of TXA, especially within $3 \mathrm{~h}$ after injuries. Therefore, TXA might be used in patients with TBI.

A large number of patients with TBI might had disability or dependent and attributed to heavy burden on the society. In this meta-analysis, we analyzed whether TXA could drop the disability or independent, but the results indicated that it could not. Meanwhile, TXA did not decrease the incidence of neurosurgery, vascular embolism, and stroke. Thus, more RCTs might be implemented to explore how to reduce the disability or dependent.

This meta-analysis supported the effect of decreasing the mortality and growth of hemorrhagic mass by comparing TXA with placebo. However, in this metaanalysis, long-term follow-up were not included in this study. More RCTs might be carried out in the future.

\section{Conclusion}

Current systematic review and meta-analysis indicated that compared with placebo, TXA (a first dose of $1 \mathrm{~g}$ in $100 \mathrm{ml}$ of normal saline in 10 to $30 \mathrm{~min}$ after admission) could reduce the mortality and growth of hemorrhagic mass in patients with TBI.

\begin{abstract}
Abbreviations
TBI: Traumatic brain injury; CENTRAL: Cochrane central register of controlled trials; TXA: Tranexamic acid; RCT: Randomized controlled trial; RR: Relative risk; Cl: Confidence interval; GCS: Glasgow coma scale
\end{abstract}

\section{Acknowledgements}

Not applicable.

\section{Authors' contributions}

CD and BL collected information and wrote articles. QM and MY designed the research and modified the article. All authors read and approved the final manuscript.

\section{Funding}

This work was supported by Science and Technology Department of Qinghai Province (No.2020-SF-136).

\section{Availability of data and materials \\ Not applicable.}

Ethics approval and consent to participate

Not applicable.

\section{Consent for publication}

Not applicable.

\section{Competing interests}

The authors declared that they had no competing interests.

\section{Author details}

${ }^{1}$ Graduate School, Qinghai University, Xining, Qinghai, China. ${ }^{2}$ Department of Neurosurgery, Xuzhou Central Hospital, Xuzhou, Jiangsu, China. ${ }^{3}$ Department of Neurosurgery, Qinghai Provincial People's Hospital, Xining, Qinghai, China.

Received: 21 January 2020 Accepted: 15 April 2020

Published online: 09 June 2020

References

1. Dewan MC, Rattani A, Gupta S, Baticulon RE, Hung Y-C, Punchak M, et al. Estimating the global incidence of traumatic brain injury. 2018;1 aop:1-18.

2. Perel P, Roberts I, Bouamra O, Woodford M, Mooney J, Lecky FJBem. Intracranial bleeding in patients with traumatic brain injury: a prognostic study. 2009;9 1:15.

3. JUHLI L, Vahlquist CJBJoD. The influence of treatment on fibrin microclot generation in psoriasis. 1983;108 1:33-7.

4. Roberts I, Shakur H, Coats T, Hunt B, Balogun E, Barnetson L, et al. The CRASH-2 trial: a randomised controlled trial and economic evaluation of the effects of tranexamic acid on death, vascular occlusive events and transfusion requirement in bleeding trauma patients. 2013;17 10:1.

5. TJTL CRASH. Effects of tranexamic acid on death, disability, vascular occlusive events and other morbidities in patients with acute traumatic brain injury (CRASH-3): a randomised, placebo-controlled trial. Lancet. 2019; 394 10210:1713-23.

6. Higgins JPJhwc-ho. Cochrane handbook for systematic reviews of interventions version 5.0. 1. The Cochrane Collaboration. 2008.

7. Moher D, Liberati A, Tetzlaff J, Altman DG, PGJP T. Reprint-preferred reporting items for systematic reviews and meta-analyses: the PRISMA statement. Phys Ther. 2009;89(9):873-80.

8. Higgins JP, Altman DG, Gøtzsche PC, Jüni P, Moher D, Oxman AD, et al. The Cochrane collaboration's tool for assessing risk of bias in randomised trials. BMJ. 2011;343:d5928.

9. Higgins JP, Thompson SG, Deeks JJ, DGJB A. Measuring inconsistency in meta-analyses. BMJ. 2003;327(7414):557-60. 
10. CRASH-2 Collaborators, Intracranial Bleeding Study. Effect of tranexamic acid in traumatic brain injury: a nested randomised, placebo controlled trial (CRASH-2 Intracranial Bleeding Study). BMJ. 2011;343:d3795..

11. Chakroun-Walha O, Samet A, Jerbi M, Nasri A, Talbi A, Kanoun H, et al. Benefits of the tranexamic acid in head trauma with no extracranial bleeding: a prospective follow-up of 180 patients. Eur J Trauma Emerg Surg. 2019;45 4:719-26.

12. Fakharian $\mathrm{E}$, Abedzadeh-Kalahroudi M, FJWn A. Effect of tranexamic acid on prevention of hemorrhagic mass growth in patients with traumatic brain injury. World Neurosurg. 2018;109:e748-e53.

13. Yutthakasemsunt S, Kittiwatanagul W, Piyavechvirat P, Thinkamrop B, Phuenpathom N, PJBem L. Tranexamic acid for patients with traumatic brain injury: a randomized, double-blinded, placebo-controlled trial. BMC Emerg Med. 2013;13 1:20.

14. Alhelaly MM, Soliman AM, Khaled A, Ellotf H, Attia MM, Elmaraezy AJT. Efficacy of tranexamic acid in traumatic brain injury: updated systematic review and meta-analysis. 2019:1460408619842736.

15. Chen $\mathrm{H}$, Chen MJTAjoem. The efficacy of tranexamic acid for brain injury: a meta-analysis of randomized controlled trials. 2019.

16. Weng S, Wang W, Wei Q, Lan H, Su J, YJWn X. Effect of tranexamic acid in patients with traumatic brain injury: a systematic review and meta-analysis. World Neurosurg. 2019;123:128-35.

17. Zehtabchi S, Baki SGA, Falzon L, DKITAjoem N. Tranexamic acid for traumatic brain injury: a systematic review and meta-analysis. Am J Emerg Med. 2014;32(12):1503-9.

18. Williams-Johnson J, McDonald A, Strachan GG, EJWIMJ W. Effects of tranexamic acid on death, vascular occlusive events, and blood transfusion in trauma patients with significant haemorrhage (CRASH-2): a randomised, placebo-controlled trial. West Indian Med J. 2010;59 6:612-24.

Ready to submit your research? Choose BMC and benefit from:

- fast, convenient online submission

- thorough peer review by experienced researchers in your field

- rapid publication on acceptance

- support for research data, including large and complex data types

- gold Open Access which fosters wider collaboration and increased citations

- maximum visibility for your research: over $100 \mathrm{M}$ website views per year

At $\mathrm{BMC}$, research is always in progress.

Learn more biomedcentral.com/submissions 